\title{
Expanding Canadian Medicare to include a national pharmaceutical benefit while controlling expenditures: possible lessons from Israel ${ }^{\text {is }}$
}

\author{
BRUCE ROSEN* \\ Myers-JDC-Brookdale Institute, Jerusalem, Israel
}

\begin{abstract}
In Canada, there is an ongoing debate about whether to expand Medicare to include a national pharmaceutical benefit on a universal basis. The potential health benefits are understood to be significant, but there are ongoing concerns about affordability. In Israel, the National Health Insurance benefits package includes a comprehensive pharmaceutical benefit. Nonetheless, per capita pharmaceutical spending is well below that of Canada and the Organization for Economic Co-operation and Development average. This paper highlights seven strategies that Israel has employed to constrain pharmaceutical spending: (1) prioritizing new technologies, subject to a global budget constraint; (2) using regulations and market power to secure fair and reasonable prices; (3) establishing an efficient pharmaceutical distribution system; (4) promoting effective prescribing behavior; (5) avoiding artificial inflation of consumer demand; (6) striking an appropriate balance between respect for IP rights, access and cost containment; and (7) developing a shared societal understanding about the value and limits of pharmaceutical spending. Some of these strategies are already in place in some parts of Canada. Others could be introduced into Canada, and might contribute to the affordability of a national pharmaceutical benefit, but substantial adaptation would be needed. For example, in Israel the health maintenance organizations (HMOs) play a central role in promoting effective prescribing behavior, whereas in HMO-free Canada other mechanisms are needed to advance this important goal.
\end{abstract}

Submitted 1 April 2017; revised 19 May 2017; accepted 1 July 2017; first published online 5 February 2018

\section{Introduction}

Israel has a well-deserved reputation as having a highly effective and efficient health system. It has impressive achievements in health status and at the same time

is Prepared for the AMS 80th Anniversary Symposium.

*Correspondence to: Bruce Rosen, Myers-JDC-Brookdale Institute, JDC Hill, POB 3886, Jerusalem 91037, Israel. Email: bruce@jdc.org 
has a relatively low level of health care spending [Organization for Economic Co-operation and Development (OECD), 2012; Moffat, 2015; Rosen, 2016a, 2016b; Clarfield et al., 2017]. Israel, 'the start-up nation' is well-known for its dynamism and creativity in the high-tech field (Senor and Singer, 2009). Similarly, in health care, Israel has been a pioneer of successful innovations in a wide range of areas. ${ }^{1}$ Israel also has an impressive ability to identify relevant health care innovations in other countries and adapt them to the Israeli context. No less important, Israel's health care system has demonstrated a remarkable capacity to establish goals, be tenacious and prioritize (Rosen et al., 2015). ${ }^{2}$

These characteristics have engendered interest in Israeli health care on the part of many countries, Canada among them. In particular, as Canada wrestles with the possibility of expanding Medicare to include prescription drug insurance, there are potential lessons to be learned from the Israeli experience. As the move to a universal drug benefit in Canada is being held up in part by cost concerns (Morgan and Boothe, 2016), Israel - with its strikingly low per capita expenditures on pharmaceuticals - may be a particularly valuable source of ideas.

Accordingly, the objective of this paper is to explore whether and how Israeli strategies for controlling pharmaceutical expenditures could be adapted to Canada and could help address the cost concerns that have impeded the adoption of a national pharmaceutical benefit.

The paper begins with an overview of Israeli health care and a comparison between the Israeli and Canadian health care systems; an overview of the Canadian system can be found elsewhere in this special issue. It then focuses in on Israel's low levels of pharmaceutical spending and the strategies it has employed to keep pharmaceutical costs low. It concludes with some initial thoughts on the relevance of the Israeli strategies to pharmaceutical coverage policy in Canada.

\section{Overview of Israeli health care}

Health care costs in Israel are remarkably low. In 2013, health accounted for only $7.5 \%$ of Israel's gross domestic product (GDP) and Israel spent only US $\$ 2428$ per capita on health (OECD Health Statistics, 2016). As indicated in Figures 1 and 2, these figures are well below those for Canada, the OECD average and the United States; in fact, they are among the lowest for all the OECD countries. Global interest in Israeli health care is thus part of a larger effort to identify frugal innovations in health systems around-the-world (Prime et al., 2016).

1 Areas in which Israeli health care has been a pioneer include using electronic health records as the basis of intensive quality improvements efforts (Rosen et al., 2011), health information exchanges (Fraenkel et al., 2013), the financing and provision of community-based long-term care services (Borowski, 2015), the systemic response to large-scale health care emergencies (Marcozzi and Lurie, 2012; Adini and Peleg, 2013), public dissemination of detailed web-based information on health rights (Brammli-Greenberg et al., 2014), the use of predictive modeling in clinical practice (Balicer et al., 2014) and the integration of physical and mental health within a managed care framework (Rosen et al., 2009).

2 See, in particular, chapter 8 . 


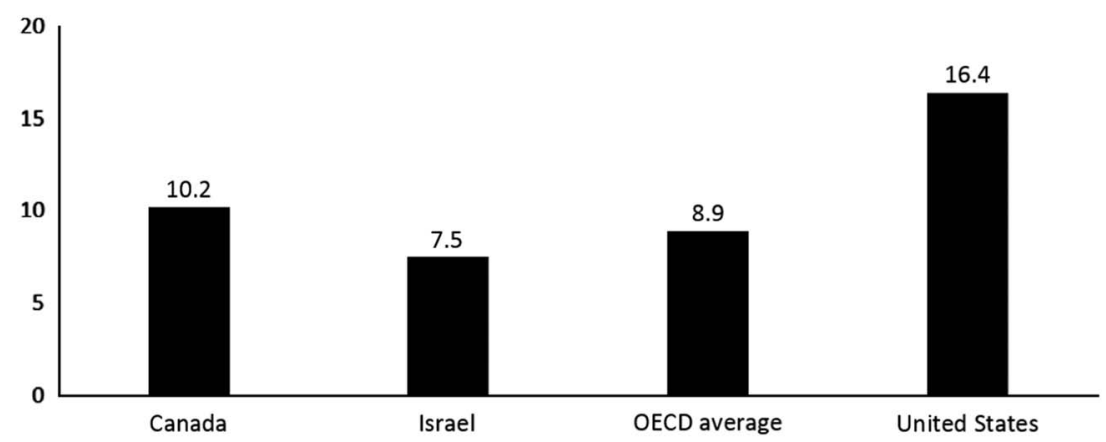

Figure 1. Health as a share of gross domestic product (\%).

Source: Organization for Economic Co-Operation and Development (OECD) Health at a Glance (2015); in most cases, the data relate to 2013.

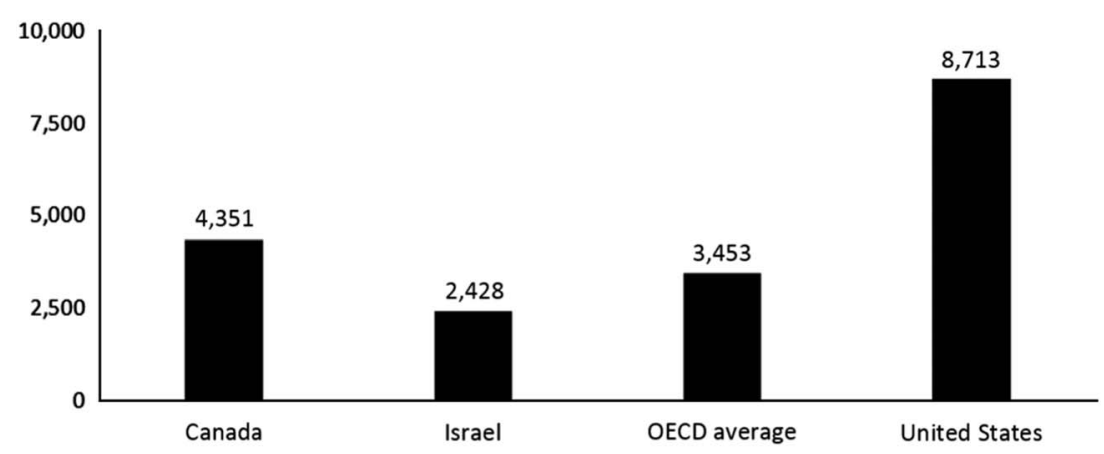

Figure 2. Per capita health spending (\$ purchasing power parity).

Source: Organization for Economic Co-Operation and Development (OECD) Health at a Glance (2015); in most cases, the data relate to 2013.

Israel has a national health insurance (NHI) system that provides universal coverage and the government spells out a broad benefits package - the goods and services to which all Israelis are entitled. All Israelis are free to choose from among four competing, non-profit health plans, which are highly regulated by government but which operate at arms-length from it. These health plans must provide their members with access to the NHI benefits package (Rosen et al., 2015).

The Ministry of Health owns and operates about half of the nation's acute care hospital beds. The largest health plan ('Clalit') operates another third of the beds, and the remainder are operated through a mix of mostly non-profit and some forprofit organizations. For-profit hospitals account for less than $5 \%$ of the acute care beds, but as of 2011 they accounted for $38 \%$ of elective operations.

The system is financed primarily via a combination of a health-specific payroll tax and general taxation. The government distributes funds among the health plans according to a capitation formula that takes into account the number of members in each plan and their mixes of age, gender and place of residence 
(center/periphery of the country). The health plans use these capitation payments, along with limited co-payments, to pay for the full spectrum of services for their members. These include hospital care, physician services, pharmaceuticals and much more. ${ }^{3}$

Thus, the health plans are the Israeli health system's main budget holders and the main organizers of care. They also work very closely with their front-line clinicians to provide them with the information, supports and incentives they need to provide high-quality and cost-effective care. While the overall physician wage scale is determined by national collective bargaining, the health plans have substantial flexibility regarding the working conditions and promotion opportunities of individual physicians. Additional information on the nature and operation of the health plans can be found in Appendix A.

While public financing remains the primary source of health system resources, the share of private financing has been increasing (Chernichovsky, 2013), rising from $32 \%$ of total health expenditure in 1995 to $39 \%$ in 2012, which is among the highest of OECD countries. The main components of private financing are co-payments for services provided in the context of NHI (primary and specialist visits and pharmaceuticals), first-dollar payments for various services not covered by NHI (primarily dental care for adults, long-term care and optical care) and voluntary health insurance (VHI) premiums. The increase in private financing is primarily due to a sharp increase in spending on VHI programs that supplement the NHI program.

The VHI programs are offered by commercial insurance companies and by the health plans themselves. Over $80 \%$ of Israelis are enrolled in health plan VHIs ${ }^{4}$ and about half are enrolled in commercial VHI. ${ }^{5}$ One of the main uses of VHI is to allow patients to pick their surgeon, a practice limited primarily to the for-profit hospitals $^{6}$ (Brammli-Greenberg et al., 2017).

Most Israeli physicians work primarily on a salaried or capitation basis for a health plan or for a governmental or non-profit hospital. Fee-for-service care is limited but growing. Some community-based specialists are paid by the health plans on a fee-for-service basis. In addition, the VHI programs pay physicians on a fee-for-service basis - typically for care provided in private hospitals but also for private, community-based consultations.

Numerous explanations have been given for Israel's low levels of health care spending. Many of these have been summarized in section 7.5 of the Israel country

3 However, as in Canada, geriatric long-term institutional care is not included in the basket of services but is partially subsidized from a separate budget (Clarfield et al., 2011; Clarfield et al., 2017).

4 People can purchase health plan VHI only from the health plan in which they are enrolled in the NHI system.

5 There is a good deal of dual coverage. Almost all Israelis with commercial VHI also have health plan VHI.

6 Choice of physician is also available via the Private Medical Services of Jerusalem's non-profit hospitals. 


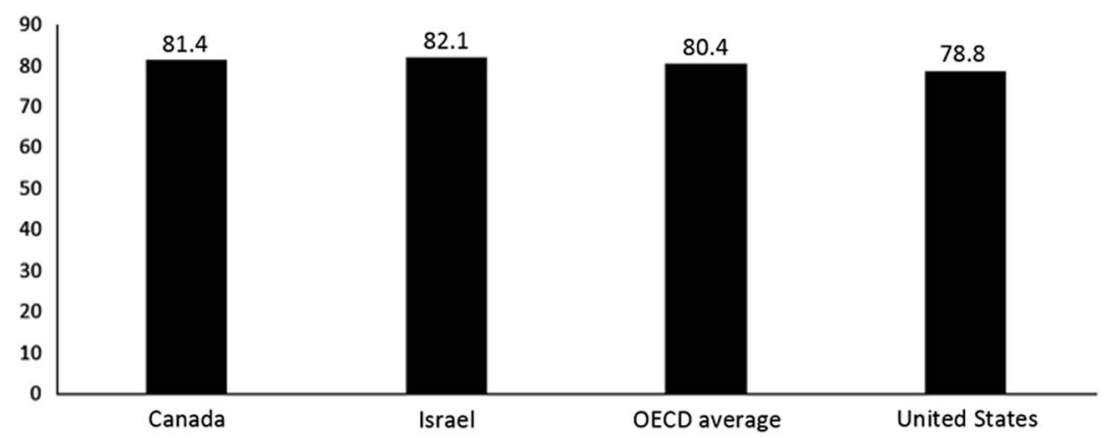

Figure 3. Life expectancy.

Source: Organization for Economic Co-Operation and Development (OECD), OECD (2015), Health at a Glance 2015: OECD Indicators, OECD Publishing, Paris. http://dx.doi.org/ 10.1787/health_glance-2015-en; in most cases, the data relate to 2013.

report for the European Observatory (Rosen et al., 2015), using the Observatory's distinction between technical efficiency and allocative efficiency. ${ }^{7}$ Zwanziger and Brammli-Greenberg (2011) look into a related issue - why Israel's health expenditures have grown relatively slowly - and they emphasize the key role of government control over the bulk of health care spending.

\section{Canadian and Israeli health care compared}

There are some significant similarities between the Israeli and Canadian health systems, including the following:

- Both have universal health care coverage, which is provided through systems that are financed and regulated by government.

- In both countries, government is not significantly involved in the direct provision of community-based services, but some of the provinces are significant (though not sole) providers of hospital services.

- Both have achieved high levels of health status, and perform well with regard to life expectancy (Figure 3), infant mortality, mortality amenable to health care, ${ }^{8}$ etc.

- US health care serves an important benchmark for both Canada and Israel often as a source of ideas about how to organize front-line care and no less often as a reminder of what we do not want to do.

Key differences include the following:

- Canada is much bigger than Israel, both geographically and in terms of population.

- Canada has a much larger economy (with a GDP of 1.6 trillion USD in 2015 compared with 0.3 trillion for Israel) and a somewhat higher per capita GDP ( 43,000 USD for Canada vs 36,000 for Israel).

7 See also the Appendix to this article.

8 Gay et al. (2011) found that both Canada and Israel had amenable mortality rates well below the OECD average. Using the Nolte and McKee list the rates were Canada - 74, Israel - 81, OECD average - 95. Note that these figures relate to data from various years between 2003 and 2006. 
- Israel has a relatively young population, with $28 \%$ under age 15 and $11 \%$ over age 64 . In Canada, only $16 \%$ of the population is under age 15 and a similar $16 \%$ is over age 64 .

- Although both countries are parliamentary democracies, Canada has a federal system and Israel has a unitary system.

- In Israel, the four competing health plans are a central feature of the health system (see Appendix A); no parallel managed care organizations exist in Canada.

- In Israel's publicly financed health care system, fee-for-service plays a secondary role in physician reimbursement; in Canada, physicians are paid predominantly on a fee-for-service basis.

- Dual practice is a significant feature of Israeli health care; in Canada dual practice is minimal, and is prohibited in some provinces.

- The two countries have different strengths and weaknesses in terms of quality of care. For example, Canada has a lower rate of admissions for coronary heart failure and hypertension (194 vs 309 per 1000 population), whereas Israel has a lower rate of patients waiting over four weeks to see a specialist ( 21 vs $62 \%$ ).

When it comes to the benefits packages of the governmental health insurance systems, there are both significant similarities as well as some important differences. Both include hospital, physician and diagnostic services in their benefits packages. Neither includes dental, ${ }^{9}$ vision or long-term care ${ }^{10}$ as universal benefits for the entire population. On the other hand, Israel's national benefits package includes community-based psychotherapy (as of 2015) and pharmaceutical care (since the inception of NHI). Neither of these are included in Canadian Medicare, though as discussed further below many Canadian provinces provide some pharmaceutical coverage. In the section that follows, we provide additional information on how the two countries differ with regard to pharmaceutical coverage and spending.

\section{Pharmaceutical coverage and spending in Israel and Canada}

In Israel, the NHI benefits package includes a comprehensive pharmaceutical benefit (Sax, 2014). Pharmaceuticals are provided primarily through the health plans and co-payments for pharmaceuticals are quite limited. ${ }^{11}$ Nonetheless, as

9 Israel's NHI does cover dental care for children.

10 In Israel a very large proportion of the population has private long-term care insurance (LTCI) and the current Minster of Health has indicated that one of his top priorities is to bring LTCI into the NHI benefits package. In Canada, some of the provinces provide substantial public funding for long-term care.

11 Coinsurance for pharmaceuticals is $15 \%$ of the purchase price for patent drugs and $10 \%$ for generic drugs, subject to a minimum co-payment of around $€ 3$ per item purchased (Ministry of Health, 2014). For the chronically ill, there is a quarterly ceiling of $\sim € 65$, varying according to health plan. Those older than 65 years who receive income support benefit from a $50 \%$ reduction in pharmaceutical coinsurance, whereas all those older than 75 years benefit from a $10 \%$ reduction; veterans of the armed forces receive a $75 \%$ discount, and Holocaust survivors are exempt from coinsurance (Office of the Deputy Director-General for 


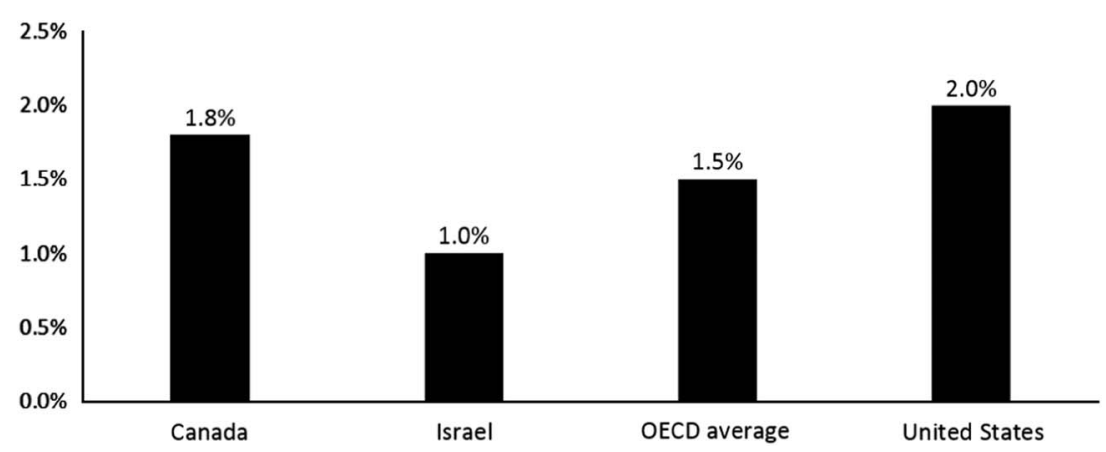

Figure 4. Pharmaceuticals as a share of gross domestic product (not including pharmaceuticals provided through hospitals).

Source: Organization for Economic Co-Operation and Development (OECD) Health at a Glance (2015); in most cases, the data relate to 2013.

illustrated in Figure 4, Israel's annual purchasing power parity per capita spending on pharmaceuticals (\$287) is far below the OECD average of $\$ 527$ as well as the Canadian level (\$761). Israel's per capita pharmaceutical expenditures are among the lowest in the OECD, and the same is true of the share of its GDP accounted for by pharmaceutical spending (Figure 5). To some extent, Israel's low spending levels are due to it having a relatively young population. However, only about a third of the Israel/Canada difference can be attributed to the difference in the age mix. After adjusting for age mix, per capita expenditures in Israel are about half of those in Canada.

In contrast, Canada does not have a comprehensive national pharmaceutical benefit as part of Medicare. In fact, 'Canada has the distinction of being the only country in the world with a universal public health insurance program that excludes coverage for prescription drugs' (Morgan et al., 2013). On the other hand, many provinces do provide pharmaceutical benefits, with almost all of them providing some coverage for seniors and some categories of social welfare recipients. Emphases differ substantially across the provinces (Daw and Morgan, 2012). For example, Ontario (Canada's largest province) offers comprehensive coverage for seniors and those on social assistance, and income-related subsidies for all others. In Quebec, employees and retirees are required to purchase private pharmaceutical coverage through their employers and there is also a mandatory provincial plan for those who do not have access to an employer-based plan. Thus, there is universal coverage in Quebec based on a mixed public/private system of finance. British Columbia, Manitoba and Saskatchewan provide catastrophic pharmaceutical coverage, with public subsidies for costs exceeding income-related deductibles.

Regulation of the Health Plans, 2014). User charges cannot be covered by supplemental health insurance programs. In a 2014 national survey of adults, $8 \%$ of respondents indicated that they had foregone at least one prescription medication over the past year due to cost. (Consider moving some of this to the main text and adding comparative data for Canada.) 


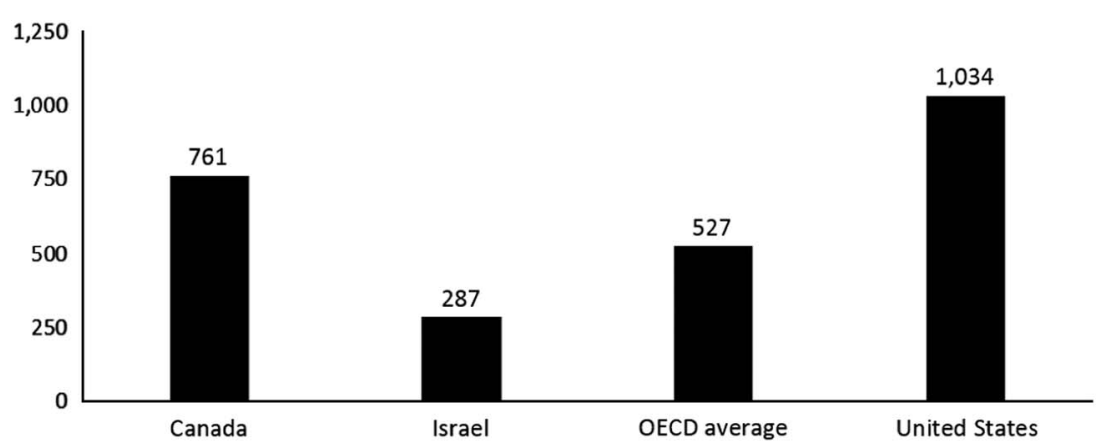

Figure 5. Per capita pharmaceutical spending (\$ purchasing power parity) (not including pharmaceuticals provided through hospitals).

Source: Organization for Economic Co-Operation and Development (OECD) Health at a Glance (2015); in most cases, the data relate to 2013.

Many Canadians are covered through private drug plans offered by employers through supplemental health benefits, but there are serious questions about whether these are cost-effective and sustainable (O'Brady et al., 2015). At $\$ 761$ per capita, pharmaceutical spending in Canada is well above the OECD average and even further above that of Israel.

For many years, there has been a debate in Canada about whether to expand Medicare to include a national pharmaceutical benefit. Proponents argue that this would significantly enhance access to pharmaceuticals and make a major contribution to the health of Canadians (Morgan et al., 2015a, 2015b; CMA, 2016). Opponents voice concerns about affordability and the impact on governmental expenditures, though these are disputed by proponents (Morgan and Boothe, 2016). Of course, a related broader issue is how much room there should be for diversity among provinces in Canadian health care.

\section{Strategies used in Israel to constrain pharmaceutical spending}

This chapter highlights seven strategies that Israel has employed to constrain pharmaceutical spending. Some of these strategies might be adaptable to Canada, and might contribute to the affordability of a national pharmaceutical benefit and/ or to the ability of provinces to make their provincial pharmaceutical programs more comprehensive.

\section{Budget constraint + prioritization ${ }^{12}$}

In 1998, Israel established a formal process for setting priorities for adding new services to the benefits package. Each year, the process begins with 'the government' (which is composed of all of Israel's ministers) deciding how much money it

12 This section benefited greatly from input from Ariel Hammerman and Ariella Toren. 
will allocate for these additions. For example, for 2013-2016 the government allocated New Israeli Shekels (NIS) 300 million per year ( 80 million USD) and for 2017 it allocated NIS 460 million. ${ }^{13}$

The key player in determining which new technologies will be funded by this annual allocation is a national public advisory committee appointed by the Minister of Health. The law stipulates that the Minister should appoint to the committee, four people from each of the following groups: leading physicians, health economists, public representatives and a representative for each of the health plans. In terms of organizational affiliations, it has always included senior officials from the Ministries of Health and Finance, as well as the representatives of the four health plans and members of 'the public'. The committee is charged with prioritizing new technologies and developing recommendations that take into account the projected health impacts of the proposed additions to the benefits package, as well as various social, economic and ethical considerations.

The committee's work is carried out with a substantial and increasing degree of transparency, including very serious media coverage. To date, the public committee's recommendations have always been adopted by the Minister of Health and the government.

In parallel with the ministerial process for setting the annual budget for new technologies, the Ministry of Health solicits proposals for new technologies/ medications (henceforth referred to as technologies) to be considered as candidates for inclusion in the benefits package. Health plans, pharmaceutical companies, the Israel Medical Association, patient organizations and other groups submit recommendations, along with supporting analytic material.

A Ministry of Health $(\mathrm{MOH})$ staff unit helps the pharmaceutical companies understand the prioritization process and its context (including Israeli health care's limited resources). As part of this, they help the companies understand that the likelihood that their proposal to add a new drug to the benefits package will succeed in the prioritization process is, in part, dependent on the price at which they are proposing to supply their new drug.

The MOH staff unit also reviews the proposals and prepares various background material for the public committee, with an emphasis on the potential health benefits of the proposed technologies. This is supplemented by the work of an economic sub-committee that provides the full committee with projections of the number of patients to use the new technologies and the cost. ${ }^{14}$ The subcommittee includes representatives from the Ministries of Health and Finance and the four health plans.

13 The budget for additions to the benefits package is determined largely by the government's overall financial abilities and priorities at the time of its annual budgetary decisions for all services and departments. The government does not consider the number, cost or need for new health technologies that year.

14 The analysis takes into account not only the impact on pharmaceutical expenditures, but also the impact on other types of expenditures such as physician services and hospital care. 
In their proposals, the companies are required to project how many Israelis will use the drug. Sometimes, a company's projection is well below the projection developed by the $\mathrm{MOH}$ staff and the economic sub-committee. ${ }^{15}$ In those cases, the pharmaceutical company will be encouraged to enter into a risk-sharing agreement with the government and the health plans. ${ }^{16,17}$ In the most common type of risk-sharing agreement, the company commits to covering the cost for all patients beyond the number they had projected.

The overall system of budgeting and prioritizing new technologies has proven to be an effective one for national decision-making. It has earned the support of the public, the relevant government ministries, the courts and the key health care providers. It has done this through a judicious mix of technical and public considerations and a growing level of transparency. ${ }^{18}$

Interestingly, the health plans' VHI programs are prohibited from covering life-saving drugs (typically for cancer care), which did not make it through the annual prioritization process. This is prohibited partly as a cost containment measure, partly to promote equity, and partly to encourage public and political support for adequate budgeting of the annual prioritization process. Note, however, that the commercial VHI programs may, and often do, provide such coverage.

\section{Fair and reasonable prices}

The Ministry of Health sets maximum prices based on the prices in a group of reference countries, which are chosen in part because their pharmaceutical prices are generally at reasonable levels. ${ }^{19}$ The health plans then use their market power

15 In some cases, this may be due to the company's desire to see the drug prioritized, and a lower projection of total cost (projected price $\times$ projected number of users) can facilitate prioritization.

16 In 2016, risk-sharing agreements were adopted for dozens different pharmaceuticals, accounting for about a third of the new technology funds allocated that year by the benefits package committee.

17 In order to create efficiency incentives for the health plans, a 'prospective budgeting method' has been adopted in which there are no budgetary amendments after the initial resource allocation. According to this method, in cases where the actual expenditures are lower than the projected expenditures, the extra funds are retained by the health plans to be used at their discretion. On the other hand, in cases where the actual expenditure is higher than projected, the health plans are not compensated by the government for their extra expenses. This approach is intended to create an incentive for the health plans to increase their efficiency. However, the health plans face a considerable financial risk if the utilization of new technologies is substantially higher than what was estimated when they were added to the benefits package. In order to handle this situation, several risk-sharing agreements have been implemented since 2011 in Israel to address financial and clinical uncertainties regarding the use of new health technologies. Some of the conceptual groundwork for this risk sharing is described in Hammerman et al. (2012).

18 The annual process (of deciding which new medications will be added to the benefits package and which will not) generates substantial media and public attention, often involving human interest stories about seriously ill patients who need medications that did not make the cut. This media attention may contribute to the interest of political leaders in lobbying the government to increase the amount allocated for new technologies.

19 In Canada, the maximum price is set as the median price for the following reference countries: France, Germany, Italy, Sweden, Switzerland, the United Kingdom and the United States. Israel sets the maximum price as the lower of the maximum price in the Netherlands and the average price in Belgium, France, Hungary and Spain. 
(mainly via an effective tender system and purchasing agreements) to secure substantial discounts from these maximum prices. The hospitals also have significant market power, as all government hospitals are served by a single government-supervised medical supplies purchasing authority. ${ }^{20}$ All of the hospitals owned by the largest health plan (Clalit) also purchase together as a group.

\section{Efficient pharmaceutical distribution system}

Most pharmaceuticals are distributed either through the health plans' own networks of pharmacies or through large, independent pharmacy chains. This creates opportunities for economies of scale that would not be achieved if each pharmacy was owned by a different family or pharmacist.

\section{Promoting effective prescribing behavior}

The health plans strongly encourage their physicians to avoid prescribing expensive medications in cases where lower-cost substitutes (either generic or patented alternatives) are likely to work just as well. The steps taken to do so vary somewhat across plans, and they include:

- Developing and disseminating policies about the clinical uses of key pharmaceuticals.

- Professional meetings led by clinical leaders with groups of physicians to discuss ways to increase the cost-effectiveness of prescribing behavior.

- Using the health plans' electronic health record systems ${ }^{21}$ to

- Limit prescriptions to those drugs listed in the health plan formulary, unless special exceptions have been granted.

- Suggest lower-cost alternatives when a physician starts to prescribe an expensive drug.

- Share with the physician real-time information on the full cost and the cost to consumer of prescriptions-in-the-making.

- Facilitate pre-authorization of certain very expensive drugs.

- Identify physicians whose prescribing behavior is significantly more expensive than that of relevant peers.

- Individual meetings of medical managers with physicians who (via the health plans' electronic health records systems) are found to be outliers with regard to prescribing behavior to both provide professional counseling and to apply carefully calibrated managerial pressure.

20 This authority has been granted an exception from the standard, and somewhat onerous, governmental purchasing regulations.

21 Note that in Israel, for over a decade all four health plans have provided all their community-based physicians with a common electronic health records system with full connectivity with health plan labs and other diagnostic services. In recent years, this has expanded into a nation-wide Health Information Exchange connecting all the health plans with all of the hospitals. 
- Managerial review of recent pharmaceutical expenditures at every level of the organizational hierarchy: physician-clinic-district-regionnational, with follow-up discussions between each manager and his subordinates.

- Employing clinical pharmacists who review patients' medical records and give feedback to physicians about rational and effective prescribing.

Information about additional features of Israeli health care that promote physician/health plan co-operation more generally (i.e. not just regarding prescribing behavior) can be found in Appendix A and in Rosen et al. (2011).

\section{Avoiding artificial inflation of consumer demand}

Israel prohibits direct-to-consumer advertising of particular branded pharmaceuticals. Regulations are being developed to allow advertising of types of medications (in keeping with the public's right to know), subject to various constraints on the nature of the messaging.

\section{The regulatory environment: striking an appropriate balance between respect for IP rights, access and cost containment ${ }^{22}$}

A recent study by Liu and La Croix (2015) reported on an index of property rights in pharmaceutical inventions and its application to 154 countries. The index incorporates five types of property rights in pharmaceuticals; six statutory measures of enforcement; and adherence to three international agreements providing for the grant and enforcement of rights to foreigners'. For 2005 (the latest date covered in the 2014 article), the index ranged from 0 in many low-income countries to a high of 4.51 in the United States followed by 3.45 in Australia, with an OECD average of 3.05. The scores for both Israel and Canada were a respectable $2.58 .^{23}$

At the same time, Israel's laws promote the availability of generics and competition among patented medications. This is done in part to contain pharmaceutical expenditures - for the government that funds the NHI pharmaceutical benefits, for the health plans that must ensure access to pharmaceuticals under NHI, and for the consumers who must bear the cost of pharmaceutical co-payments. These constraints on expenditures also facilitate access - both at the level of the consumer (for whom co-payments can sometimes deter purchase of prescribed medication) and at the macro level (enabling the addition of more new pharmaceuticals to the benefits package within the government-determined budget constraint).

22 This section draws heavily on input from Eyal Schwartzberg, Israel's chief pharmacist and the head of the pharmaceutical divisions at the Israel Ministry of Health.

23 Unpublished data for 2014, received from the authors, indicates that the scores for Israel and Canada remained stable, whereas the OECD average increased to 3.61 . 
Examples of relevant regulations are as follows:

- In Israel, local and other generic manufacturers can oppose a patent before its registration. In contrast, in the European Union and the United States, objections can be raised only after a patent has been granted.

- Data exclusivity periods in Israel are shorter than in Europe and the United States, thus allowing for quicker preparation and evaluation of applications for approval of generics.

- Israel allows for the importing of generics from all 28 member states of the European Union, the United States, Canada, Australia, Switzerland, New Zealand and Japan (also known as authorized countries). This promotes greater competition than is available in most countries.

- There are special regulations for generics that are already registered with the US Food and Drug Administration or the European Medicines Agency, which shorten the registration time from Israel's usual 270 days to only 70 days.

- There is a prioritization procedure, which provides expedited consideration for the first two generics that can provide a convincing case that they would reduce total annual expenditure by at least 10 million NIS.

- When a physician specifies a brand name drug in a prescription, pharmacists are allowed to switch to a generic substitute, except in those cases where the physician explicitly indicated that this should not be done (Yariv, 2015; Nathan et al., Forthcoming).

Israel's openness to generics is probably due, in part, to Israel being the home of Teva, one of the world's leading manufacturers of generics. Moreover, none of the leading manufacturers of patented medications are based in Israel. Nonetheless, as indicated in its performance in the Liu and La Croix study cited above, as a responsible member of the international community, Israel balances its openness to generics with serious respect for the intellectual property rights of pharma companies based in other countries.

\section{Developing shared societal understandings about the value and limits of pharmaceutical spending}

In Israel, there is a broad consensus that:

a. pharmaceuticals can make a significant and unique contribution to health;

b. our society cannot afford all the pharmaceuticals we would like to have;

c. we should therefore be judicious about the adoption of pharmaceuticals at the macro/policy level and about their use at the micro/care delivery level; and

d. cost containment efforts should give particular attention to newer and particularly expensive pharmaceuticals.

This shared societal understanding is, in part, a result of the annual prioritization process and the broad media coverage of that process. In turn, this shared understanding makes it easier for Israel to implement the broad range of practical measures reviewed in this paper. 


\section{The relevance to Canada of the Israeli strategies}

Table 1 provides an overview of the extent to which each of the seven Israeli strategies for containing pharmaceutical expenditures is already deployed in Canada and the potential for adaptation to the Canadian scene.

As indicated in the table, two of the strategies - efficient distribution systems and the avoidance of artificial inflation of consumer demand - are already deployed in Canada. ${ }^{24}$ With regard to those strategies, Israel probably does not have any new ideas or models to offer Canadian policymakers.

Canada already does have drug prioritization processes, with comprehensive health technology assessments of new medications and other new technologies carried out at the federal level ${ }^{25}$ and prioritization decisions made at the provincial level (aside from Quebec). ${ }^{26}$ One wrinkle that Israel has to offer Canadian policymakers for their consideration is that, as noted above, each year all the proposed pharmaceuticals are considered simultaneously rather than sequentially, once a year, subject to a budget constraint.

This feature is somewhat unique to Israel; it is important because it forces the country to grapple head-one with difficult prioritization decisions. It also forces government to be frank with the public about the unavoidability of budget constraints - even with regard to health - and their implications. In addition, it means that even 'blockbuster' medications, which have no competitors addressing the same clinical need, nonetheless must compete for limited public funds with other candidates for inclusion in the benefits package (many of which seek to address totally different clinical challenges).

Canada's federal system of government and the current patchwork system of providing partial pharmaceutical benefits through numerous provincial plans might make it difficult to implement these Israeli practices. Parallel prioritization processes in several provinces could lead to populist competitive pressures. This would be avoided if Canada adopted a national pharmaceutical benefit, which would also contribute to economies of scale in implementing a single, broadscope, prioritization process.

24 Under federal law, Canada does not allow prescription drug advertising to the public. Since 2001, this has meant that full product ads, which include brand names and health claims, are not allowed. In 2001, a reinterpretation of an existing regulation allowed reminder ads, which include the brand name but not health claims (Mintzes, 2006). As in other jurisdictions that prohibit direct to consumer advertising, diseaseoriented or help-seeking ads, which do not mention specific brands or treatments, represent a regulatory gray area. Canadians are also exposed to full product ads that originate in the United States (Mintzes, 2009).

25 Created in 1989 by Canada's federal, provincial and territorial governments, formerly, the Canadian Coordinating Office for Health Technology Assessment, was born from the idea that Canada needs a coordinated approach to assessing health technologies. It operates the Canadian Drug Review for noncancer drugs and the pan-Canadian Oncology Drug Review for cancer drugs. CADTH assesses a pharmaceutical only after Health Canada has approved it for sale in Canada after assessing its safety, clinical effectiveness and the quality of its manufacturing process, https://www.ccra-acrc.ca/images/CommunityForum/PrePARE-how-cancer-drug-funding-decisions-are-made.pdf

26 See https://www.cadth.ca/about-cadth 
Table 1. Israeli strategies for containing pharmaceutical expenditures and their relevance to Canada

\begin{tabular}{|c|c|c|}
\hline Israeli strategy & Current status in Canada & Potential for adaptation to Canada \\
\hline $\begin{array}{l}\text { Budget constraint and } \\
\text { prioritization }\end{array}$ & $\begin{array}{l}\text { Technology assessments at the } \\
\text { federal level; decisions about } \\
\text { funding at the provincial level }\end{array}$ & $\begin{array}{l}\text { Setting an annual budget for new } \\
\text { technologies. } \\
\text { Employing an annual prioritization } \\
\text { process where all candidates are } \\
\text { considered simultaneously, as } \\
\text { opposed to sequential consideration } \\
\text { of candidates. } \\
\text { Encouraging pharma companies to } \\
\text { share in the financial responsibility } \\
\text { for their utilization projections }\end{array}$ \\
\hline $\begin{array}{l}\text { Fair and reasonable prices } \\
\text { Gov't max prices } \\
\text { Bulk purchasing } \\
\text { Health plan discounts }\end{array}$ & $\begin{array}{l}\text { Pan-Canadian price negotiations and } \\
\text { provincial price negotiations; } \\
\text { review board for excessive pricing }\end{array}$ & $\begin{array}{l}\text { Changing the list of reference countries } \\
\text { to give more weight to countries } \\
\text { which are more effective in securing } \\
\text { lower prices }\end{array}$ \\
\hline $\begin{array}{l}\text { Efficient distribution system } \\
\text { through large pharmacy } \\
\text { chains }\end{array}$ & $\begin{array}{l}\text { Large chains dominate in Canada as } \\
\text { well }\end{array}$ & $\begin{array}{l}\text { Israel probably does not have anything } \\
\text { new to offer }\end{array}$ \\
\hline $\begin{array}{l}\text { Health plan promotion of } \\
\text { effective prescribing } \\
\text { behavior of individual } \\
\text { MDs: } \\
\text { Timely information } \\
\text { Pre-authorizations } \\
\text { Profiling and review }\end{array}$ & $\begin{array}{l}\text { Have not yet found evidence of } \\
\text { anything analogous in Canada }\end{array}$ & $\begin{array}{l}\text { Given Canada's lack of health plans } \\
\text { and culture of physician } \\
\text { independence, this would require } \\
\text { significant adaptation. There could } \\
\text { be roles for physician groups, } \\
\text { regional health authorities, and/or } \\
\text { medical associations }\end{array}$ \\
\hline $\begin{array}{l}\text { Avoiding artificial inflation } \\
\text { of consumer demand: } \\
\text { Prohibition of direct-to- } \\
\text { consumer advertising }\end{array}$ & Already exists in Canada & $\begin{array}{l}\text { Israel does not have anything new } \\
\text { to offer }\end{array}$ \\
\hline $\begin{array}{l}\text { Regulatory framework that } \\
\text { is pro-generic and pro- } \\
\text { competition }\end{array}$ & $\begin{array}{l}\text { Canada has some, but not all, of the } \\
\text { pro-generic features of the Israeli } \\
\text { system }\end{array}$ & $\begin{array}{l}\text { Proximity to the United States could } \\
\text { create a political barrier }\end{array}$ \\
\hline $\begin{array}{l}\text { Developing a shared } \\
\text { societal understanding }\end{array}$ & Beginning to emerge in Canada & $\begin{array}{l}\text { Complicated somewhat by the lack of } \\
\text { a national pharmaceutical benefit }\end{array}$ \\
\hline
\end{tabular}

Additional features of the Israeli approach may be more adaptable to Canada the involvement of all key players in the prioritization process; using the prioritization process to secure concessions on both components of overall expenditure - price and volume; and a growing level of transparency. Canadian policymakers are encouraged to give them careful consideration.

Another Israeli strategy noted above is to ensure fair and reasonable prices. Canada also has taken significant steps to do so. Canada has a Patented Medicine Prices Review Board (PMPRB, 2016) to ensure that patentees do not abuse their patent rights by charging consumers excessive prices, and a major effort is underway to review and improve the PMPRB's effectiveness. In addition, several 
provinces either set or negotiate maximum prices, taking advantage of their market power (which is significant in the case of the larger provinces).

Moreover, all 13 Provinces and Territories have been working together to achieve greater value for brand name and generic drugs for publicly funded drug programs through the pan-Canadian Pharmaceutical Alliance (pCPA). ${ }^{27,28}$ Their work includes various types of market entry agreements with Pharma companies. This sometimes includes elements of risk sharing, though to date these are apparently less prevalent than in Israel.

An important feature of the Israeli system is that, in addition to having government set maximum prices, the health plans negotiate discounts. However, in the absence of health plans, it is not immediately obvious how Canada can parallel Israel's second-stage discount negotiations. Another feature of the Israeli approach might be more easily adopted in Canada - ensuring that the set of countries used for reference pricing is composed primarily of countries which have been successful in securing relatively low prices.

Perhaps the most striking difference between Israel and Canada comes from the capacity of Israeli health plans to work closely with their physicians on prescribing behavior. This same close working relationship is one of the most important factors in Israel's successes in a wide range of areas that go far beyond pharmaceuticals - including containing overall health care costs and improving quality (Rosen et al., 2011). This is not something that Canada can easily adapt, as it has no health plans and its physicians are highly independent.

However, perhaps a uniquely Canadian approach can be crafted to provide physicians with the incentives and institutional supports needed to promote cost-effective prescribing behavior. This could perhaps involve efforts by provincial governments, regional health authorities, medical associations, pharmacist associations and others - either separately or through collaborative efforts.

Encouragingly, the Canadian Medical Association (CMA) has called for promoting more appropriate prescribing behavior, emphasizing that this should be done in a non-coercive manner (CMA, 2011, 2016). Advances in web connectivity, health IT, artificial intelligence and cloud computing may soon make it easier for countries without health plans - such as Canada - to craft new ways to promote appropriate prescribing. It is noteworthy that, between 2009 and 2015, the proportion of doctors using electronic health records increased from 37 to $73 \%{ }^{29}$

CADTH's Optimal Use Program constitute another feature of the Canadian system that could be built upon. This program creates tools and decision aids which can be used by regional drug programs and clinicians to promote effective prescribing behavior.

27 See http://www.pmprovincesterritoires.ca/en/initiatives/358-pan-canadian-pharmaceutical-alliance

28 The confidential price agreements negotiating by the pCPA are not binding on the individual provincial drug plans.

29 See 'Family Doctors See Improvements for Patients; Canada Still Lags Peer Countries' on the website of the Canadian Institute for Health Information. 
Moreover, many Canadian provinces have tiered pricing, which give consumers a financial incentive to prefer generics over branded medications. This probably also affects prescribing patterns somewhat, as many clinicians are sensitive to patients' financial burdens.

In terms of the regulatory environment, Canada - like Israel - has numerous policies to promote generics and competition among branded drugs. This includes generic substitution on the part of pharmacists and the tiered pricing noted above. On the other hand, there are a number of pro-generic and pro-competition features of the Israeli regulatory framework, which do not currently exist in Canada. Canadian policymakers might want to consider the pros and cons of adapting them to the Canadian context.

Regarding shared societal understandings, Canada may have recently started on the pathway to a consensus about the value and affordability of pharmaceuticals. The extensive series of meetings which the Canadian legislature held this year about pharmacare, and the works of people like Morgan, Boothe, Adams, appear to be contributing to a shared understanding of the challenges facing Canada and ways in which it can be addressed.

Interestingly, and perhaps not surprisingly, the consensus emerging in Canada appears to be somewhat different from the consensus in Israel. In contrast with the Israeli consensus, in Canada the general public does not appear to have a shared understanding that prioritization of new pharmaceuticals can enhance affordability and may be necessary to make a government-funded pharmaceutical benefit affordable and sustainable. This may be less crucial in Canada than in Israel, as Canadian health care has more resources at its disposal in terms of dollars per person.

On the other hand, experts around-the-world are predicting that innovations in oncology and personalized medicines will put growing pressures on pharmaceutical budgets. As a result, in the years ahead Canada may also feel a pressing need for tougher prioritization and, if so, it could be helpful for the public understand the need for such prioritization.

Either way, Canadian health and political leaders may want to take steps to further crystallize a Canadian consensus - one that is particularly tailored to Canada's priorities, values, resources.

\section{Conclusions}

The Israeli experience suggests that to get value for money in pharmaceutical care it can be very helpful to engage a very broad set of actors, work on both shared understandings and practical arrangements, and move forward at both the macro/ policy level and the micro/care delivery level.

Although Israel and Canada differ in many ways (e.g. geographical size, population and system of government), their health systems share several key features (e.g. universal, largely publicly funded coverage and high levels of health). In light of these similarities and differences, there are definitely opportunities for 
cross-national learning between these two countries, including with regard to pharmaceutical cost containment.

However, these learning opportunities must be pursued with due caution and simple copy/paste transfer of cost containment approaches should be avoided. One key difference that precludes simple transfers is that in Israel the health plans play a central role in organizing care and providing front-line clinicians with the information, supports and incentives needed to contain costs. No parallel organizations exist in Canada. Thus, while some of Israel's strategies for controlling pharmaceutical costs may be transferrable to Canada, at the level of tactics substantial adaptation would still be needed.

Several of Israel's seven major strategies for containing pharmaceutical expenditures may offer new approaches that can be adapted to Canada. Some of these could be relevant for provincial and even private pharmaceutical plans; however, their effect would probably be greatest in the case of a Canada-wide pharmacare benefit.

Morgan et al. (2015a, 2015b) have estimated the cost of a universal drug benefit for Canada. They found that 'Universal public drug coverage would likely yield substantial savings to the private sector with comparatively little increase in costs to government'. Adaptation to Canada of various strategies deployed in Israel could further strengthen that conclusion.

\section{Acknowledgments}

This manuscript was prepared at the request of AMS, in conjunction with an invitation to present at the AMS 80th anniversary symposium. The AMS also provided generous financial support for the effort. The author's understanding of the Israeli pharmaceutical sector benefited greatly from the input of Eyal Schwartzberg, Dan Greenberg, Ariel Hammerman, Ariella Toren, Shmuel Klang and David Mossinson. The author's understanding of the Canadian pharmaceutical sector benefited greatly from input from Katherine Boothe, Tanya Potashnik, Owen Adams, Barry Jones and Robert Schwartz. Many of the above provided valuable comments on earlier versions of this manuscript, as did Greg Marchildon, Colleen Flood, Matthew Brougham, Carolyn Tuohy, Stephen Duckett, Joann Trypuc, Mark Clarfield, Etan Diamond, Moriah Ellen, Ruth Waitzberg and two anonymous reviewers.

\section{References}

Adini, B. and K. Peleg (2013), 'On constant alert: lessons to be learned from Israel's emergency response to mass-casualty terrorism incidents', Health Affairs, 32(12): 2179-2185.

Balicer, R. D., C. J. Cohen, M. Leibowitz, B. S. Feldman, I. Brufman, C. Roberts and M. Hoshen (2014), 'Pneumococcal vaccine targeting strategy for older adults: customized risk profiling', Vaccine, 32(8): 990-995.

Borowski, A. (2015), 'Israel's long-term care social insurance scheme after a quarter of a century', Journal of Aging \& Social Policy, 27(3): 195-214.

Brammli-Greenberg, S., R. Waitzberg, T. Medina-Artom and A. Adijes-Toren (2014), 'Low-budget policy tool to empower Israeli insureds to demand their rights in the healthcare system', Health Policy, 118(3): 279-284. 
Brammli-Greenberg, S., R. Waitzberg and R. Gross (2017), 'Integrating public and private insurance in the Israeli health system: an attempt to reconcile conflicting values', in Thomson, S. (ed.), Private Health Insurance and Medical Savings Accounts: Lessons From International Experience, Cambridge, UK: Cambridge University Press.

Canadian Medical Association (CMA) (2011), A Prescription for Optimal Prescribing, Ottawa: CMA.

Canadian Medical Association (CMA) (2016), National Pharmacare in Canada: Getting from Here to There, Ottawa: CMA.

Chernichovsky, D. (2013), 'Reforms are needed to increase public funding and curb demand for private care in Israel's health system', Health Affairs, 32(4): 724-733.

Clarfield, A. M., H. Bergman and R. Kane (2001), 'Fragmentation of care for frail older people - an international problem. Experience from three countries: Israel, Canada, and the United States', Journal of the American Geriatrics Society, 49: 1714-1721.

Clarfield, A. M., O. Manor, G. B. Nun, S. Shvarts, Z. S. Azzam, A. Afek, F. Basis and A. Israeli (2017), Health and health care in Israel: an introduction. The Lancet https://oi.org/ 10.1016/S0140-6736(17)30636-0.

Daw, J. R. and S. G. Morgan (2012), 'Stitching the gaps in the Canadian public drug coverage patchwork? A review of provincial pharmacare policy changes from 2000 to 2010', Health Policy., 104(1): 19-26.

Fraenkel, M., D. Chinitz, C. A. Salzberg and K. Reichman (2013), 'Sustainable health information exchanges: the role of institutional factors', Israel Journal of Health Policy Research, 2: 21.

Gay, J. G., V. Paris, M. Devaux and M. de Looper (2011), 'Mortality amenable to health care in 31 OECD countries: estimates and methodological issues', OECD Health Working Papers No. 55, OECD Publishing, Paris.

Hammerman, A., P. Feder-Bubis and D. Greenberg (2012), 'Financial risk-sharing in updating the national list of health services in Israel: stakeholders' perceived interests', Value in Health, 15(5): 737-742.

Liu, M. and S. La Croix (2015), 'A cross-country index of intellectual property rights in pharmaceutical inventions', Research Policy, 44(1): 206-2016.

Marcozzi, D. and N. Lurie (2012), 'Measuring healthcare preparedness: an all-hazards approach', Israel Journal of Health Policy Research, 1: 42.

Mintzes, B. (2006), Direct-To-Consumer Advertising of Prescription Drugs in Canada: What are the Public Health Implications?, Toronto, ON: Health Council of Canada.

Mintzes, B. (2009), 'Should Canada allow direct-to-consumer advertising of prescription drugs?', Canadian Family Physician, 55(2): 131-133.

Moffat, A. R. (2015), Health-Care Check-Up: Whose System is Least Efficient?, Bloomberg.

Morgan, S. G. and K. Boothe (2016), 'Universal prescription drug coverage in Canada - longpromised yet undelivered', Healthcare Management Forum, 29(6): 247-254.

Morgan, S. G., J. R. Daw and M. R. Law (2013), 'Rethinking pharmacare in Canada'. C.D. HOWE Institute, Commentary \#384, Toronto, ON.

Morgan, S. G., M. Law, J. R. Daw, L. Abraham and D. Martin (2015a), 'Estimated cost of universal public coverage of prescription drugs in Canada', CMAJ, 187(7): 491-497.

Morgan, S. G., D. Martin, M. A. Gagnon, B. Mintzes, J. R. Daw and J. Lexchin (2015b), Pharmacare 2020: The Future of Drug Coverage in Canada, Vancouver, BC: Pharmaceutical Policy Research Collaboration, UBC.

O’Brady, S., M. A. Gagnon and A. Cassels (2015), 'Reforming private drug coverage in Canada: inefficient drug benefit design and the barriers to change in unionized settings', Health Policy, 119(2): 224-231. 
Organization for Economic Co-Operation and Development (OECD) (2012), OECD Reviews of Health Care Quality: Israel 2012, Paris: OECD.

Organisation for Economic Co-Operation and Development (OECD) Health Statistics (2016), http://www.oecd.org/els/health-systems/health-data.htm [1 May 2017].

Patented Medicine Prices Review Board (PMPRB) (2016), PMRB Guidelines Modernization Discussion Paper, Ottawa: PMPRB.

Prime, M. S., Y. A. Bhatti, M. Harris and A. Darzi (2016), 'Frugal innovations for healthcare: a toolkit for innovators', Academy of Management Proceedings, 2016(Meeting Abstract Supplement): 1262.

Rosen, B. (2016a), 'Adaptation of Health Care Innovations from Other Countries'. Brookdale Briefings - Inside Israel's Social Challenges, Youtube video clip from Myers-JDCBrookdale Institute, Jerusalem.

Rosen, B. (2016b), The Israeli Health Care System' in International Health Care System Profiles, New York: The Commonwealth Fund.

Rosen, B., N. Nirel, R. Gross, S. Bramali and Noa Ecker (2009), 'The Israeli mental health insurance reform', The Journal of Mental Health Policy and Economics, 11(4): 201-208.

Rosen, B., L. G. Pawlson, R. Nissenholtz, J. Benbassat, A. Porath, M. R. Chassin and B. E. Landon (2011), 'What the United States could learn from Israel about improving the quality of health care', Health Affairs, 30(4): 764-772.

Rosen, B., R. Waitzberg and S. Merkur (2015), "Israel: Health System Review". Health Systems in Transition, Copenhagen: European Observatory of Health Systems and Policies.

Sax, P. (2014), 'The shaping of pharmaceutical governance: the Israeli case', Israel Journal of Health Policy Research, 3: 16.

Schwartzberg, E., J. P. Nathan, B. Rosen and E. Marom (2018), 'Pharmacy in Israel'. American Journal of Health System Pharmacy, 75(1): e57-e61.

Senor, D. and S. Singer (2009), Start-Up Nation - The Story of Israel's Economic Miracle, New York: Council on Foreign Relations.

Yariv, H. (2015), 'The case of pharmacist prescribing policy in Israel', Israel Journal of Health Policy Research, 4: 49.

Zwanziger, J. and S. Brammli-Greenberg (2011), 'Strong government influence over the Israeli health care system has led to low rates of spending growth', Health Affairs, 30(9): 1779-1785.

\section{Appendix A}

\section{How Israel's system of competing, non-profit health plans contributes to quality efficiency and equity}

In Israel's NHI system, the health plans have overall responsibility for the health of their members and receive pre-paid capitation payments from the government to finance that care. As a result, they have strong incentives to be cost conscious in their care provision. This is further encouraged by the fact that Israelis rarely switch plans so that, unlike US health plans, the Israeli plans have an incentive to invest in the health of their members to reduce future expenses. The health plans also have an incentive to be responsive and keep their members happy as Israelis have a right to switch plans at any time. Finally, as the budget holders, health 
plans not only have the incentives to organize care effectively, they also have the capacity to do so.

Some of the steps taken by the health plans to constrain expenditures include:

- Development of strong organizational structures going from national to regional to district levels, with clear performance goals, annual work programs, monitoring and accountability.

- Performance of extensive hospital utilization review.

- Development of a broad array of community-based services that serve as substitutes for hospital care (e.g. an extensive network of community-based specialists, home care services, emergency care centers, call centers, etc.).

- The creation of electronic health record systems linking all of a health plan's clinicians and diagnostic centers.

- Encouraging the development of the primary care physicians (PCPs) as care coordinators.

- Working with PCPs largely on a salaried or capitation basis, to align incentives.

Another key feature of the Israeli situation is the extensive monitoring and publication of findings regarding health care performance in a range of areas. The Myers-JDC-Brookdale Institute carries out a bi-annual survey of consumers' interactions with their health plans. The $\mathrm{MOH}$ monitors and publicizes information health plan finances. The QiCH project monitors and publicizes information on clinical quality of care. The media summarize and transmit to the public the key findings from these monitoring efforts in a way that the public can understand and then use in its choices of health plans. These information are also used by $\mathrm{MOH}$ in its regulatory role.

Interestingly, the health plans have been very active in promoting equity, even though they do not have any clear financial incentives to do so. A skeptic might contend that these efforts are done primarily for public relations purposes; to find favor with the regulator (the $\mathrm{MOH}$ ). However, the breadth and intensity of these efforts seem to transcend PR. My own reading of the situation is that they emanate primarily from the professionalism and values of the health plan leaders and their employees at all levels. In addition, the status of the health plans as non-profit organizations governed by publicly minded boards of directors, also plays an important role. 